\title{
Alunos com Surdez no Brasil: Espaços de Escolarização e Produção Acadêmica em Três Diferentes Contextos Regionais ${ }^{1}$ \\ STUDENTS With DEAFNesS in BRAZIL: SpaCes of SCHOOLING AND ACADEMIC Production in ThreE Different ReGional ConteXts ${ }^{2}$
}

\author{
Carlos Henrique Ramos SOARES ${ }^{3}$ \\ Claudio Roberto BAPTISTA ${ }^{4}$
}

\begin{abstract}
RESUMO: Este artigo apresenta resultados de uma pesquisa que teve como objetivo analisar a escolarização de alunos com surdez, considerando os índices educacionais e a produção acadêmica sobre essa temática, em três estados brasileiros. $\mathrm{O}$ interesse em pesquisar esse fenômeno é justificado pela ampliação do debate contemporâneo sobre a escolarização dos alunos com deficiência e pela ocorrência de mudanças na legislação educacional brasileira que indicam que a escolarização desses alunos deve ocorrer nas salas de aula comuns do Ensino Regular. Trata-se de um estudo de natureza qualitativa realizado com base na análise documental associada à revisão bibliográfica e à busca de indicadores de escolarizaçáo. Foi possível identificar que ocorreram intensas alteraçōes na escolarização de alunos com surdez, com o aumento das matrículas no Ensino Regular e a reduçáo das matrículas no Ensino Especial, com maior ênfase nos Estados do Espírito Santo e de São Paulo e em menor proporçáo no Estado do Rio Grande do Sul. Em relação à produção acadêmica desenvolvida por Programas de Pós-Graduaçăo em Educaçấo nos diferentes estados, percebeu-se que as temáticas investigadas com maior frequência mostram sintonia com as alteraçóes que ocorreram nos contextos de referência de cada programa.
\end{abstract}

PALAVRAS-CHAVE: Educação Especial. Surdez. Inclusão Escolar. Produção acadêmica.

\begin{abstract}
This paper presents results of a research that had as objective to analyze the schooling of pupils with deafness, considering the educational and academic production indexes on this theme, in three Brazilian States. The interest in researching about this phenomenon is justified by the increased contemporary debate on the schooling of students with disabilities and by the changes in the Brazilian educational laws, which indicates that the schooling of these pupils must occur in the common classrooms of Regular Education. The study has a qualitative nature, and it was based on documentary analysis, combined with bibliographical revision and the search of schooling indexes. It was possible to identify that there were intense changes in the schooling of students with deafness, with the increase of school enrollment in Regular Education and the decrease of school enrollment in Special Education; this happened especially in the States of Espírito Santo and São Paulo, and with lower frequency in the State of Rio Grande do Sul. Regarding the academic production developed by Graduate studies programs in Education in the different states, it was perceived that the themes investigated with higher frequency are linked to the changes that occurred in the contexts of reference of each program.
\end{abstract}

KEYWORDS: Special Education. Deafness. School Inclusion. Academic production.

\section{INTRODUÇÃo}

A presente pesquisa tem como objetivo analisar a escolarização de alunos com surdez, considerando os índices de matrícula e a produção acadêmica (teses e dissertaçóes) sobre essa temática, em três estados brasileiros. Para a realização do estudo, elegeu-se como foco a pesquisa desenvolvida no Programa de Pós-Graduação em Educação da Universidade Federal do Rio Grande

\footnotetext{
${ }^{1}$ http://dx.doi.org/10.1590/S1413-65382418000400007

${ }^{2}$ Apoio Financeiro: Coordenação de Aperfeiçoamento de Pessoal de Nível Superior - CAPES.

${ }^{3}$ Doutor em Educaçáo pela Universidade Federal do Rio Grande do Sul (UFRGS). Professor da Rede Municipal de Ensino de Porto Alegre - RS, Brasil.chr_soares@yahoo.com.br.

${ }^{4}$ Doutor em Educação pela Università degli Studi di Bologna. Professor pela Faculdade de Educação e pelo Programa de Pós-Graduação em Educação da Universidade Federal do Rio Grande do Sul (UFRGS), Porto Alegre - RS, Brasil. baptistacaronti@yahoo.com.br.
} 
do Sul (UFRGS), no Programa de Pós-Graduação em Educação da Universidade Federal do Espírito Santo (UFES) e no Programa de Pós-Graduação em Educação Especial da Universidade Federal de São Carlos (UFSCar), durante o período de 2005 a 2015. A escolha desses programas foi motivada pela importância regional, pelos elevados índices na avaliação do sistema de PósGraduação realizada pela CAPES e, no caso da UFSCar, pela singularidade de ênfase temática na área da Educação Especial. Trata-se de um grupo de programas consolidados, com ampla experiência na formação de pesquisadores e pertencentes ao sistema federal de educação.

O interesse em pesquisar essa temática, nesse momento histórico, justifica-se pela ocorrência de mudanças significativas na legislação educacional brasileira, com ênfase da escolarização dos alunos com essas características no ensino comum, em espaços compartilhados entre alunos surdos e ouvintes. Trata-se de um tema de elevada complexidade, em função da importância de definirmos quem são efetivamente esses alunos, quais suas necessidades em termos de apoio educacional e como esses apoios têm se traduzido na ação de diferentes profissionais que se associam à alternância de espaços variados no contexto das escolas. $\mathrm{O}$ que tem ocorrido com relação às matrículas desses alunos? Quais são os direcionamentos predominantes na pesquisa acadêmica relativamente a esses fenômenos? Essas são nossas perguntas geradoras. Nosso ponto de partida foi a identificação que os três diferentes contextos regionais mostram distintos direcionamentos de matrículas, segundo os dados fornecidos pelo Censo Escolar do Instituto Nacional de Estudos e Pesquisas Educacionais Anísio Teixeira (INEP), considerando os alunos surdos e com deficiência auditiva ${ }^{5}$ nas diferentes modalidades da Educação Básica. Tais diferenças referem-se à manutenção de grande número de alunos no ensino exclusivamente especializado ou de fortalecimento da escolarização em escolas e classes comuns.

No que se refere ao plano metodológico, de acordo com Silva e Gamboa (2011), o presente estudo insere-se em uma perspectiva que pode ser descrita como a "pesquisa da pesquisa" e pretende contribuir com a reflexão sobre o conhecimento relativo a uma temática específica. Para a realização do trabalho investigativo, houve buscas no banco de teses e dissertaçóes da CAPES e nos repositórios digitais das referidas universidades para a constituição do corpus de análise. Os descritores utilizados foram: surdez, deficiência auditiva, pessoa surda, aluno surdo, estudos surdos, educação de surdos, inclusão de surdos, cultura surda, Libras e língua de sinais. Todos os trabalhos referidos foram lidos, com especial atenção dirigida aos resumos, às palavras-chave, à parte introdutória e às consideraçóes finais. Na sequência, procuramos identificar os assuntos, os objetivos, os resultados e as discussóes que foram realizadas pelos pesquisadores. Com relação aos passos para a análise documental, seguimos as orientaçóes de Lima e Mioto (2007), buscando trabalhar com filtros que assegurassem a inclusão de trabalhos compatíveis com os objetivos do estudo e uma análise processual que, a partir de sucessivas leituras, pudesse colher os elementos de mais interesse.

Com a finalização desse processo, organizamos um quadro mais amplo sobre as produções relativas à surdez dessas três instituiçóes. Assim, obtivemos um material capaz de ofe-

\footnotetext{
${ }^{5}$ A caracterização dos alunos surdos e com deficiência auditiva está presente no Art. 2o do Decreto no 5.626/2005. Conforme esse documento, a pessoa surda é aquela que, por ter perda auditiva, compreende e interage com o mundo por meio de experiências visuais, manifestando sua cultura principalmente pelo uso da Língua Brasileira de Sinais. No que tange à deficiência auditiva, o Decreto considera aquela pessoa com perda bilateral, parcial ou total, de quarenta e um decibéis ou mais, aferida por audiograma nas frequências de $500 \mathrm{~Hz}, 1.000 \mathrm{~Hz}, 2.000 \mathrm{~Hz}$ e $3.000 \mathrm{~Hz}$ (Decreto $\mathrm{n}^{\circ} 5.626 / 2005$ ). Destacamos que, no âmbito do presente texto, esses dois grupos são denominados "alunos com surdez" ou "alunos surdos".
} 
recer subsídios não só para o alcance dos objetivos propostos por este trabalho, como também para a realização de novas pesquisas.

$\mathrm{Na}$ análise de indicadores educacionais, com atenção dirigida às matrículas e aos espaços de escolarização, trabalhamos com os microdados do Censo Escolar do INEP, acessados por meio do programa SPSS (Statistical Package for the Social Sciences), na busca de identificação dos contingentes que permitem a reflexão acerca das alteraçóes na escolarização no Ensino Regular e no Ensino Especial ${ }^{6}$.

\section{EdUCAÇÃo DE ALUNOS COM SURDEZ: MARCOS LEGAIS E NORMATIVOS}

Inicialmente, destacamos algumas transformaçóes que ocorreram na legislação educacional de nosso país, a partir do movimento de valorização legal da Língua Brasileira de Sinas (Libras). Em 2002, o reconhecimento dessa língua como meio legal de comunicação e expressão encontrou respaldo na Lei no 10.436 (2002), que a legitimou como língua oficial dos brasileiros com surdez. Na sequência, com a publicação do Decreto no 5.626/2005, a referida lei foi regulamentada, e, nesse documento, foram estabelecidas mudanças significativas no âmbito educacional, tendo como objetivo garantir o acesso e a permanência dos alunos surdos no Ensino Regular. Além disso, o Decreto tornou-se um documento importante para os processos de escolarização desses estudantes porque aponta também diretrizes sobre a formação de professores de Libras, sobre o uso e a difusão da Libras e da Língua Portuguesa nos ambientes educacionais e sobre a formação de tradutores e intérpretes de Libras.

Em 2008, o Ministério da Educação apresentou a Política Nacional de Educação Especial na Perspectiva da Educação Inclusiva (2008). As diretrizes propostas por esse documento trouxeram novas definições para a escolarização dos alunos surdos no contexto da escola de ensino comum. Podemos observar que o Atendimento Educacional Especializado previsto no texto dessa política deve ser ofertado tanto na modalidade oral e escrita quanto na língua de sinais, realizado mediante a atuação de profissionais com conhecimentos específicos no ensino de Libras e de Língua Portuguesa na modalidade escrita como segunda língua (Política Nacional de Educação Especial na Perspectiva da Educação Inclusiva, 2008).

Como se percebe, foi a partir do reconhecimento da Libras como a língua oficial dos brasileiros com surdez que diferentes açóes foram tomadas com o intuito de difundir o seu uso nos sistemas de ensino, sinalizando a realização de uma série de investimentos, que vão desde a formação de novos profissionais, até a produção de materiais didático-pedagógicos acessíveis para serem usados com os alunos em sala de aula.

Apesar desses avanços temos presenciado, nas últimas décadas, a continuidade de uma polarizaçáo que tende a opor alternativas educacionais que buscam reunir os alunos surdos e ouvintes, ou aquelas que defendem a manutenção de espaços de presença exclusiva de alunos surdos. Essa polarização tem se mostrado com maior força no contexto acadêmico, visto que, no âmbito das diretrizes políticas, como já afirmamos, há uma ênfase muito clara na primeira perspectiva - a inclusão escolar. No contexto acadêmico, essa polarização continua a existir e

${ }^{6}$ No âmbito do presente texto usaremos a mesma terminologia apresentada pelo Censo Escolar: Modalidade Ensino Regular e Modalidade Ensino Especial. 
não há uma uniformidade entre os estudos da área, pois podemos identificar a defesa de espaços de escolarização exclusiva (Lodi, 2013) ou, ainda, o debate sobre as vantagens de espaços mistos para a escolarização (Damázio, 2007). No entanto, essa relação entre o cotidiano resultante de uma história política brasileira e os estudos acadêmicos sobre o tema mobiliza-nos a buscar evidências que mostrem avanços na compreensão relativa a essa complexa temática.

A seguir, em sintonia com as diretrizes políticas já anunciadas, pode-se observar um incremento no número de matrículas desses estudantes em classes comuns do ensino regular.

\subsection{OS ESPAÇOS DE ESCOLARIZAÇÃO DOS ALUNOS COM SURDEZ}

Sobre os índices educacionais, descrevemos a seguir alguns dados ${ }^{7}$ fornecidos pelos censos escolares de 2007 e 2016 com o objetivo de identificar a distribuição de matrículas de alunos com surdez segundo as modalidades de Ensino - Regular, Especial e Educação de Jovens e Adultos (EJA).

Os gráficos foram organizados considerando os números totais de matrículas do Brasil e de cada estado onde estão inseridas as três universidades que integram o presente estudo. Vale lembrar que, dentro desse contexto, estão computados os números de matrícula dos alunos surdos e com deficiência auditiva das redes privada e públicas de ensino, estando, nesta última, presentes as esferas estadual, municipal e federal.

Os dados apresentados no Gráfico 1 correspondem a um universo de 65.078 matrículas para o ano de 2007 e de 71.664 matrículas para o ano de 2016, evidenciando um aumento do número de matrículas de alunos com surdez e deficiência auditiva na Educação Básica brasileira.

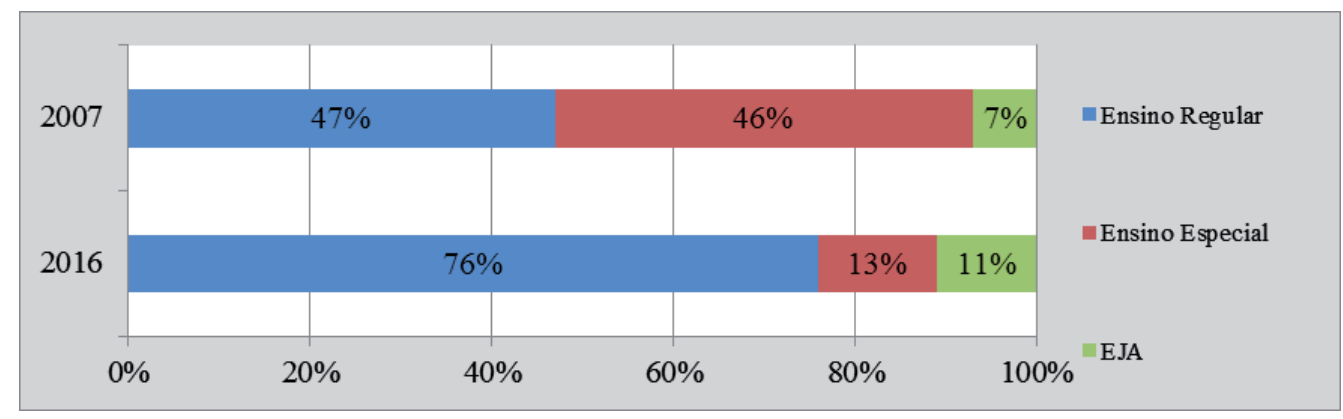

Gráfico 1. Distribuição de matrículas de alunos com surdez na Educação Básica do Brasil por modalidade de ensino (2007 e 2016)

Fonte: Anais do Encontro Interinstitucional de Pesquisa (2014); Instituto Nacional de Estudos e Pesquisas Educacionais Anísio Teixeira [INEP] (2016).

Ao longo do período analisado, também é possível observar mudanças significativas tanto no âmbito do Ensino Regular como no contexto do Ensino Especial. Entre 2007 e 2016,

\footnotetext{
${ }^{7}$ As informaçôes do Censo Escolar referentes ao ano de 2007 foram extraídas dos Anais do Encontro Interinstitucional de Pesquisa: políticas públicas e escolarização de alunos com deficiência. Banco de Dados: Sorocaba/ SP: CAPES/Inep, 2014. Outro aspecto importante, que merece ser destacado, diz respeito ao início do marco temporal escolhido, pois é somente a partir de 2007 que os microdados do Censo Escolar podem ser acessados de forma detalhada no site do INEP.
} 
o índice de alunos com essas características que frequentavam o Ensino Regular no Brasil foi de 30.476 (47\%) matrículas em 2007 e de 54.581 (76\%) em 2016. Paralelamente a esse movimento, ocorreu uma redução expressiva do número de matrículas no Ensino Especial, passando de 30.026 (46\%) matrículas, em 2007, para 9.061 (13\%) matrículas em 2016. Na EJA, o número de matrículas sobe de 4.576 (cerca de 7\%), em 2007, para 8.022 (11\%), em 2016.

Como se percebe, os dados descritos no Gráfico 1 mostram que as diretrizes propostas pelos marcos normativos citados anteriormente têm mostrado sintonia com alteraçóes presentes na distribuição de matrículas de alunos surdos na Educação Básica brasileira. No entanto, como veremos a seguir, tais alteraçóes ocorrem de forma diferenciada nos estados onde estão situadas as universidades investigadas. Essa diferenciação foi um dos elementos disparadores da presente investigação, pois consideramos três estados que se mostram como exemplares na análise do cenário brasileiro. Como veremos a seguir, em 2016, o Estado de São Paulo apresentou índices de matrícula muito semelhantes à media nacional. Em modo muito distinto, os outros dois estados representam os extremos de um variado espectro, pois o Rio Grande do Sul mostra-se como aquele que apresenta maior percentual de alunos com surdez no ensino especial, e o Espírito Santo é aquele onde podemos encontrar um maior percentual desses alunos incluídos no ensino comum, dentre todos os estados da federação. Essa configuração de matrículas suscita a necessidade de ampliar nossa compreensão sobre o fenômeno e de buscar subsídios para que nosso conhecimento contemple outras dimensóes do processo. $\mathrm{O}$ conhecimento acadêmico não gera necessariamente as diretrizes políticas, mas se constitui como parte de vozes de atores sociais integrantes de um pensamento reconhecido como válido em determinado tempo histórico. Após a análise dos índices de matrículas, ocupar-nos-emos da análise da pesquisa sobre o tema nesses contextos.

Os dados do Rio Grande do Sul (Gráfico 2) mostram que, em 2007, ocorreram 3.549 matrículas de alunos com surdez e deficiência auditiva e que, em 2016, houve um aumento para 4.792 matrículas.

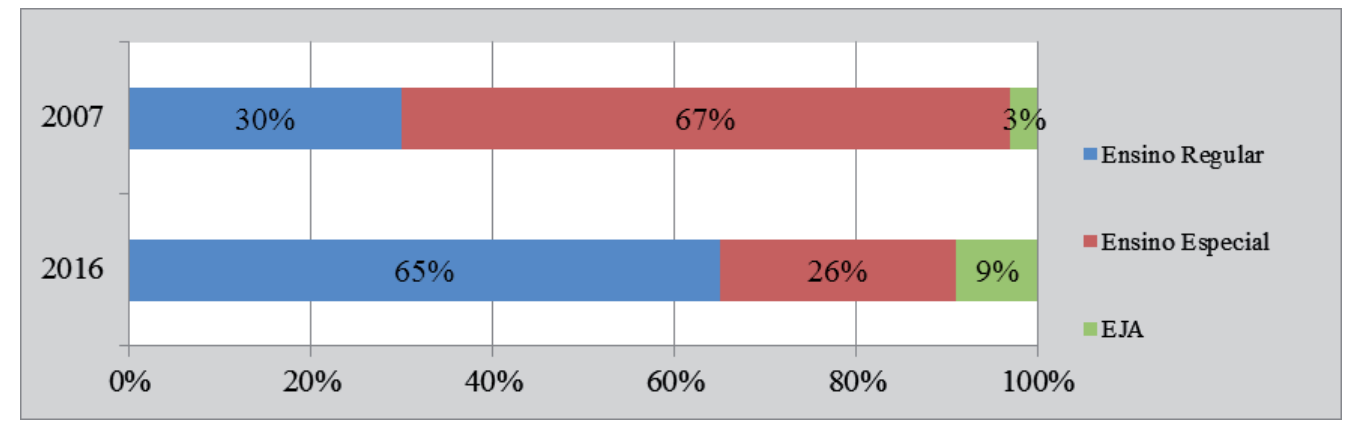

Gráfico 2. Distribuição de matrículas de alunos com surdez na Educação Básica do Estado do Rio Grande do Sul por modalidade de ensino (2007 e 2016)

Fonte: Anais do Encontro Interinstitucional de Pesquisa (2014); INEP (2016).

No Ensino Regular, foram efetuadas 1.049 (30\%) matrículas, em 2007, e 3.128 (65\%) matrículas, em 2016. No Ensino Especial, ocorreu uma redução de 2.382 (67\%) matrículas, em 2007, para 1.262 (26\%), em 2016. Na EJA, o percentual de alunos sobe de 3\% (118 
matrículas), em 2007, para 9\% (402 matrículas), em 2016. Esses índices permitem afirmar que, apesar de estarem ainda abaixo da média nacional, as matrículas presentes na modalidade de Ensino Regular tiveram um aumento significativo entre os anos de 2007 e 2016.

Os números totais de matrículas de alunos com surdez e deficiência auditiva nas escolas do estado de São Paulo (Gráfico 3) correspondem a 12.600 matrículas para o ano de 2007 e 12.911 matrículas para o ano de 2016.

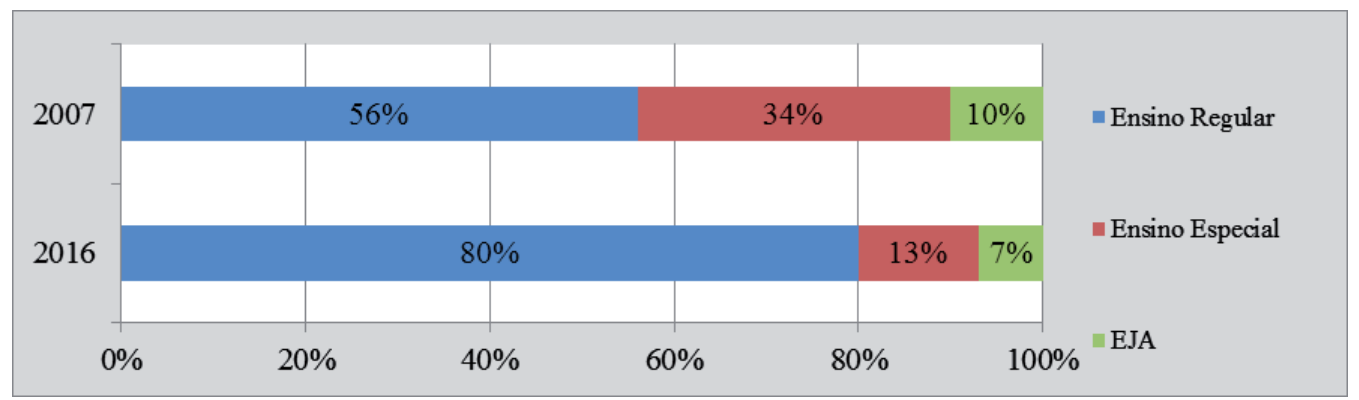

Gráfico 3. Distribuição de matrículas de alunos com surdez na Educação Básica do Estado de São Paulo por modalidade de ensino (2007 e 2016)

Fonte: Anais do Encontro Interinstitucional de Pesquisa (2014); INEP (2016).

Durante o período analisado, o número de matrículas no Ensino Regular passou de 7.143 (56\%), em 2007, para 10.316 (80\%), em 2016. No Ensino Especial, o número total de matrículas sofreu uma redução significativa, passando de 4.297 (34\%), em 2007, para 1.637 (13\%), em 2016. Na EJA, o percentual de alunos teve uma pequena variação, reduzindo de 10\% (1.160 matrículas), em 2007, para 7\% (958), em 2016. Esses indicadores mostram que as alteraçóes que ocorreram no estado de São Paulo acompanham a média nacional, com uma intensificação de matrículas no Ensino Regular e uma significativa redução dos números do Ensino Especial.

Os índices do Estado do Espírito Santo (Gráfico 4) correspondem a um total de 1.224 matrículas, em 2007, e de 937 matrículas, em 2016.

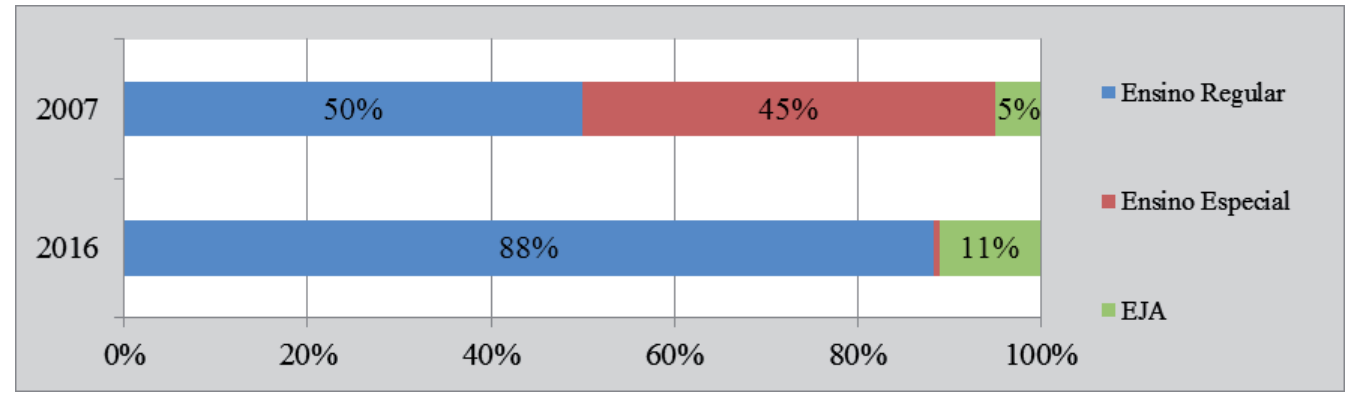

Gráfico 4. Distribuição de matrículas de alunos com surdez na Educação Básica no Estado de Espírito Santo por modalidade de ensino - 2007 e 2016

Fonte: Anais do Encontro Interinstitucional de Pesquisa (2014); INEP (2016). 
A análise desses números evidencia que, apesar de ter ocorrido um declínio no número total de matrículas no contexto geral, os dados do Ensino Regular aumentaram de forma expressiva, passando de 607 (50\%) matrículas, em 2007, para 825 (88,06\%) matrículas, em 2016. De modo concomitante a esse significativo aumento, observa-se uma redução acentuada de matrículas no Ensino Especial, as quais passaram de 552 (45\%) matrículas, em 2007, para 5 (0,53\%), em 2016. Na EJA, porém, pôde-se observar um aumento do número de matrículas, passando de 65 (5\%), em 2007, para 107 (11,41\%), em 2016.

Após análise do mapeamento da distribuição das matrículas de alunos com surdez e deficiência auditiva, é possível observar que os dados dos três estados analisados mostram um progressivo aumento no âmbito do Ensino Regular em sintonia com os indicadores brasileiros em sua totalidade. Isso aconteceu com maior ênfase no contexto do Espírito Santo e em menor proporção no Rio Grande do Sul, estado que, mesmo evidenciando um aumento de matrículas no Ensino Regular, apresentou, em 2016, o maior percentual de estudantes matriculados no ensino exclusivamente especializado.

É possível observar que os dados que compóem os gráficos 1, 2, 3 e 4 sinalizam que há um movimento associado às matrículas em consonância com as diretrizes propostas pelos atuais marcos normativos no sentido de ampliação da escolarização nas salas de aula comuns do Ensino Regular. Além dessas evidências, a análise desses índices mostra que tem ocorrido uma variação quantitativa nas matrículas relativas à EJA, como espaço de escolarização desses alunos, particularmente nos estados do Rio Grande do Sul e do Espírito Santo.

$\mathrm{Na}$ continuidade do trabalho, procuramos conhecer a produção acadêmica dos Programas de Pós-Graduação em Educação da UFRGS e da UFES e do Programa de PósGraduação em Educação Especial da UFSCar, com o objetivo de encontrar pistas sobre o que está sendo investigado nesses três diferentes contextos regionais. As motivaçóes para esse direcionamento de nossa investigação estão associadas à compreensão de que a pesquisa acadêmica possui vínculos com seus contextos de produção. Ainda que seja importante reconhecer que a investigação deva estar dirigida ao novo, ao desconhecido, sem estar necessariamente vinculada a fenômenos locais, quando se trata de fenômenos sociais e humanos, são frequentes as suposições de que a relevância atribuída a alguns temas possa produzir efeito na busca de conhecimento. Por outro lado, os resultados das investigaçóes passam a ser elementos de potencial mudança, em termos de diretrizes, não apenas nos contextos de pertinência imediata.

\subsection{ProduÇÃo aCADÊMICA SObRe EDUCAÇÃo DE ALUNOS COM SURDEZ: UM OLHAR SOBRE AS PESQUISAS}

Para facilitar a compreensão dos dados, organizamos os próximos gráficos tendo como diretrizes de análise: o número total de produçôes; as modalidades de ensino e os temas escolhidos pelos pesquisadores. Dessa forma, apresentamos, no Gráfico 5, o número total de teses e de dissertaçóes sobre educação de alunos com surdez que foram produzidas pelos Programas de Pós-Graduação das três instituições analisadas durante o período de 2005 a 2015. 


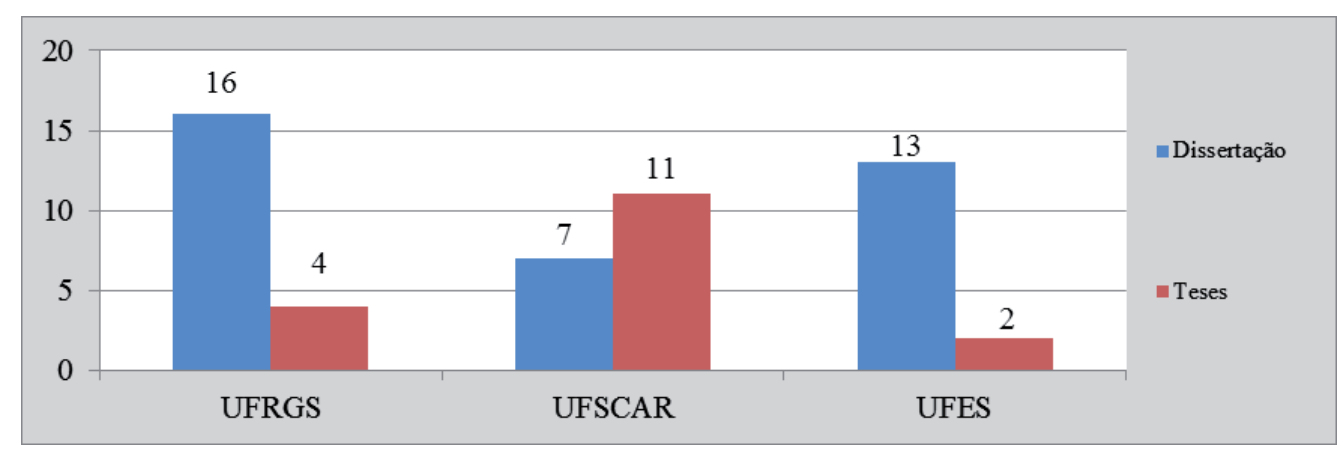

Gráfico 5. Produção de teses e dissertaçóes sobre educação de alunos com surdez na UFRGS, UFSCAR e UFES (2005-2015)

Fonte: Biblioteca de teses e dissertaçôes da CAPES e repositório digital das respectivas universidades.

No conjunto de produções, foram encontradas 36 dissertações de Mestrado e 17 teses de Doutorado. No entanto, gostaríamos de destacar que organizamos o Gráfico 5 procurando diferenciar o número de produçóes acadêmicas de cada universidade. Observa-se que a UFRGS produziu, ao longo desse período, 20 trabalhos (16 dissertaçóes e quatro teses), a UFSCar produziu 18 trabalhos (sete dissertaçóes e 11 teses) e a UFES realizou a produção de 15 trabalhos (13 dissertaçóes e duas teses). Nota-se que não há uma grande disparidade em relação à quantidade total de trabalhos produzidos por cada uma das instituiçóes, mas há um predomínio de teses no contexto da UFSCar.

Após esse levantamento, procuramos caracterizar as modalidades de ensino - Ensino Regular, Ensino Especial e EJA presentes como contexto educativo - e os temas das referidas produçóes por meio das informaçóes presentes em seus títulos, resumos, palavras-chave e objetivos. Em grande parte dos casos, tivemos de recorrer à leitura do texto em sua totalidade, pois nem sempre as informaçóes buscadas estavam presentes na fase introdutória do trabalho.

No Gráfico 6, identificamos quais foram as modalidades de ensino contempladas como contexto investigativo com maior frequência pelos pesquisadores das três universidades.

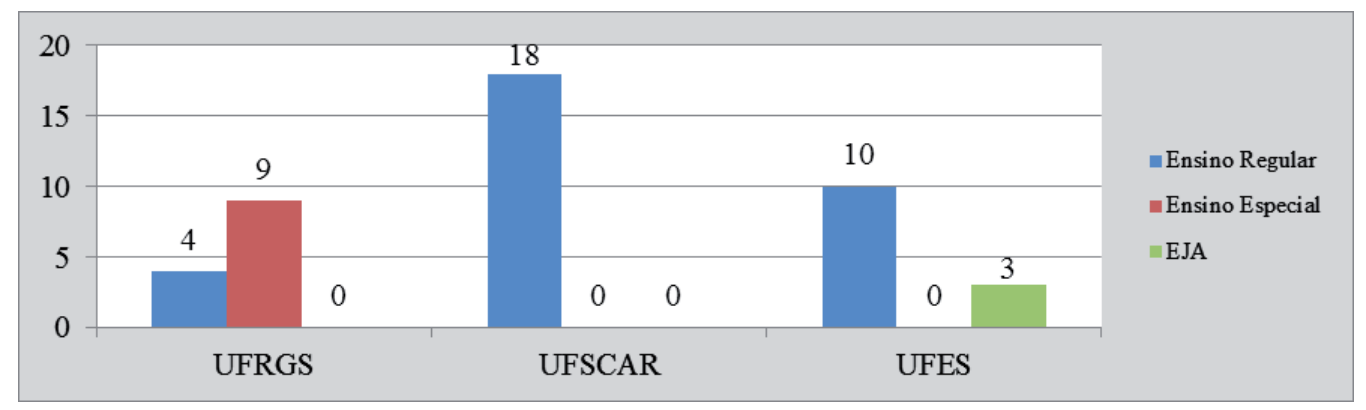

Gráfico 6. Modalidades de ensino contempladas pela produção de teses e dissertaçôes sobre educação de alunos com surdez (2005-2015)

Fonte: Biblioteca de teses e dissertaçôes da CAPES e repositório digital das respectivas universidades. 
Como mostra o Gráfico 6, o Ensino regular foi a modalidade de ensino investigada com maior frequência na UFSCar (100\% das pesquisas) e na UFES (67\% das produçóes). Já, do total de vinte investigaçóes realizadas pela UFRGS, essa modalidade esteve presente em quatro trabalhos (20\% das pesquisas). Em relação aos dados do Ensino Especial, chama atenção o fato de que esse contexto só fez parte dos interesses investigativos de pesquisadores vinculados à UFRGS, com nove trabalhos produzidos (45\% das investigaçóes dessa instituição). Sobre os dados referentes à EJA, foi possível observar que a UFES foi a única universidade a realizar estudos envolvendo essa modalidade, com três trabalhos encontrados (20\% de suas produçóes) ${ }^{8}$.

Após o mapeamento das modalidades de ensino investigadas, iniciamos o trabalho de caracterização dos temas predominantes. Seguindo as ideias de Tonello, Lunardelli e Almeida Junior (2012), priorizamos, nesse processo, a releitura dos resumos, com especial atenção à escolha das palavras-chave que foram utilizadas pelos pesquisadores de cada universidade.

No âmbito da UFRGS, as palavras-chave que foram citadas com maior frequência foram: educação de surdos (7 trabalhos); discurso (4) e inclusão (4); estudos culturais (3), Libras (3) e AEE (3); cultura surda (2), intérprete (2), educação bilíngue (2) e Educação Especial (2).

Percebemos que, nesse contexto acadêmico, a maior parte das produçóes critica as diretrizes que estão presentes nos documentos legais relativas à implementação no cenário brasileiro de uma política educacional inclusiva para alunos com surdez. Essas pesquisas utilizam como referencial teórico autores dos estudos culturais para justificar a valorização de um discurso de defesa de uma cultura surda e de uma educação bilíngue que se dedique ao ensino de Libras e da Língua Portuguesa em escolas especializadas somente para alunos com surdez. Percebeu-se também que, por considerarem a surdez uma diferença cultural, esses estudos frequentemente procuram desvincular a educação de surdos do campo da Educação Especial. Além disso, algumas diretrizes educacionais que incentivam os processos de inclusão escolar são criticadas e vistas como estratégias de governamento e disciplinamento dos ouvintes sobre os surdos.

Evidenciando essa tendência, as informações contidas no Gráfico 6 mostram que, dentre as instituiçóes analisadas, o PPGEdu da UFRGS, entre os anos de 2005 e 2015, foi o único Programa de Pós-Graduação que priorizou, em suas investigaçóes, temáticas que envolvessem o contexto da escola especial para alunos surdos. Nesse grupo estão, por exemplo, os estudos realizados por Marins (2015), Alberton (2015), E. V. L. Silva (2013), Fülber (2012), Furtado (2012) e Kuchenbecker (2011).

Diferentemente desse direcionamento, as pesquisas realizadas por Suzana (2014), Soares (2011) e Finck (2009) são exemplos de produções que sinalizam a possibilidade de qualificação do trabalho educativo em contextos de inclusão escolar. Realizadas em espaços de ensino comum, essas produçóes propuseram-se a investigar tanto a organização do currículo escolar, contemplando alunos surdos e ouvintes no mesmo espaço educativo, como também os serviços de apoio especializado que podem ser oferecidos em diferentes espaços e tempos da escola.

No contexto da UFSCar, as palavras-chave citadas e os temas abordados com maior frequência pelos pesquisadores foram: inclusão (8 trabalhos); Educação Especial (7); intérprete

\footnotetext{
${ }^{8}$ Nos casos da UFRGS e da UFES, houve trabalhos nos quais não havia a indicação de um contexto empírico vinculado a uma modalidade de ensino.
} 
(5) e aluno surdo (5); deficiência auditiva (4) e Libras (4); formação profissional (3); professor interlocutor (2), educação bilíngue (2) e surdez (2).

Como vimos anteriormente, o número de matrículas de alunos com surdez e deficiência auditiva na modalidade de Ensino Regular aumentou significativamente ao longo dos últimos anos no Estado de São Paulo, com índices que se aproximam da média nacional. É provável que essa nova configuração contextual tenha relaçóes com os objetivos considerados prioritários pelos pesquisadores da UFSCar, no sentido de abordarem prioritariamente essa modalidade de ensino em suas investigaçóes. Nesse contexto acadêmico, encontramos reflexóes sobre a implementação do Atendimento Educacional Especializado, sobre a educação bilíngue associada a investigar o ensino de Libras e da Língua Portuguesa, assim como análises acerca da importância de intensificar e qualificar a formaçáo profissional dos envolvidos com o processo de inclusão de alunos com surdez.

Chama atenção o número de estudos que analisou as funções exercidas pelos tradutores intérpretes de língua de sinais, identificados também como intérpretes educacionais, além do trabalho do professor interlocutor de Libras ${ }^{9}$. A atuação desses profissionais foi pesquisada por Menezes (2014), Santos (2014), Caetano (2014), Santos (2013) e Jordão (2013). Percebemos também que alguns autores refletiram sobre o ensino da Língua Portuguesa para alunos com surdez (Furlan, 2011; Sella, 2009; Bandini, 2006) e outros investigaram temas que, apesar de terem aparecido com menor frequência, problematizaram questóes desafiadoras que perpassam os processos de educação de muitos alunos com surdez. Fazem parte desse grupo: o trabalho que descreveu e analisou o desempenho acadêmico de alunos surdos usuários de implante coclear (Brazarotto, 2008); a tese de Cozendey (2013), que buscou analisar o uso de vídeos bilíngues como recursos pedagógicos para o ensino de conceitos da disciplina de Física; e o trabalho de Cambruzzi (2013), que analisou a eficiência das adaptaçóes visuais nas atividades apresentadas para um aluno surdocego com síndrome de Usher.

De modo geral, percebeu-se que essas investigaçóes reconhecem a existência de barreiras que dificultam o processo de inclusão de alunos surdos no ensino comum. No entanto, os trabalhos realizados por esses pesquisadores favorecem a reflexão sobre a possibilidade de se construir espaços qualificados e mistos, com evidências de oportunidades educativas para os alunos ouvintes e para aqueles com surdez.

Dando continuidade a esse processo de mapeamento e identificação das palavras-chave e dos temas abordados pelas produçóes, descrevemos a seguir as pesquisas vinculadas ao Programa de Pós-Graduação em Educação da UFES.

Nos trabalhos da UFES, as palavras-chave citadas com maior frequência foram: Libras (4 trabalhos); educação bilíngue (3), surdez (3), inclusão (3) e tradução (3); mediação (2), alfabetização (2), EJA (2), Educação Infantil (2) e criança surda (2). Percebe-se que há indícios de que os interesses investigativos dos pesquisadores da UFES vão ao encontro de um contexto que reduziu de forma significativa as matrículas do ensino especializado para alunos

${ }^{9} \mathrm{O}$ cargo de professor interlocutor de Libras foi criado de acordo com a Resolução no 38/2009 da Secretaria de Educaçáo do Estado de São Paulo. Em seu artigo 1º, a Resolução destaca que esse profissional atuará nas escolas de rede estadual de ensino e terá como função assegurar aos alunos surdos ou com deficiência auditiva o acesso às informaçóes e aos conhecimentos curriculares dos ensinos fundamental, médio e da educação de jovens e adultos (Resolução SE no 38, 2009). 
com surdez. A variabilidade dos assuntos procurou abordar diferentes temas associados ao processo de inclusão desses alunos em todas as etapas do ensino regular e da EJA.

É importante destacar o número significativo de estudos que problematizaram a complexidade do trabalho desenvolvido pelos diferentes profissionais de apoio para alunos com surdez. Nesse grupo, podemos citar como exemplo as pesquisas desenvolvidas por Rodrigues (2009), Rocha (2012), Vieira-Machado (2012), Xavier (2012), Rabelo (2014) e Costa Junior (2015). Nessa amostra, encontramos estudos que analisaram, entre outros assuntos, a elaboração do Atendimento Educacional Especializado organizado pelas equipes bilíngues ${ }^{10}$ e a complexidade do trabalho de tradução e mediação realizado pelos intérpretes de língua de sinais.

$\mathrm{Na}$ análise das produçóes realizadas pela UFES, destacamos também dois trabalhos que nos ajudam a refletir sobre como é complexa a tarefa de analisar as diferentes formas de viver de um sujeito com surdez e como essa diversidade influencia diretamente seu processo de escolarizaçáo. Enquanto Costa (2007) analisa e valoriza o movimento capixaba pela luta do reconhecimento dos surdos como sujeitos culturais e não mais como os deficientes auditivos da Educação Especial, J. A. S. Silva (2013) mostra-nos a experiência de vida de uma criança que fez a cirurgia para colocar o implante coclear, que circula por diferentes espaços, que se reconhece como surda usuária de Libras e que, apesar disso, não nega as novas possibilidades de convivência e interação proporcionadas pela oralidade e pelo uso do implante ao se relacionar com familiares, professores e colegas ouvintes não usuários de Libras.

$\mathrm{Na}$ amostra de trabalhos realizados pela UFES, percebemos que existe o reconhecimento de que os alunos com surdez possuem necessidades linguísticas diferentes e que, por isso, precisavam ser atendidos por profissionais devidamente capacitados. De forma geral, essas pesquisas indicaram também que a convivência e a experiência de participar de grupos nos quais há o desafio da Língua Portuguesa, da Libras e de outras formas de comunicação pode ser rica para os alunos surdos, para os alunos ouvintes, para professores e demais integrantes da comunidade escolar.

\section{ConsideraÇóes FinaIs}

Como se pode observar, ao longo do presente trabalho, procuramos colocar em evidência a escolarização dos alunos com surdez. Para isso, analisamos a produção acadêmica em três diferentes estados brasileiros representados por Programas de Pós-Graduação na área da Educação escolhidos intencionalmente.

Vale lembrar que foram considerados para a análise os direcionamentos propostos pela legislação educacional vigente e as transformaçóes que ocorreram na distribuição de matrículas nos estados onde essas universidades estão inseridas. Partimos da compreensão de que uma política, em seu processo de implementação, é geralmente permeada por uma variabilidade que decorre de influências e interpretaçóes associadas a contextos específicos, como analisam Muller e Surel (2002). No caso da temática que envolve surdez e escolarização, observa-se que essa multiplicidade interpretativa tende a confirmar as duas perspectivas anunciadas em mo-

${ }^{10}$ De acordo com Rabelo (2014), a política de educação bilíngue do município de Vitória/ES distribui as matrículas dos alunos surdos em sete escolas de ensino regular. Esses espaços possuem equipes bilíngues formadas por professores bilíngues Libras/Língua Portuguesa, professores de Libras, instrutores de Libras, além de tradutores e intérpretes de Libras/Língua portuguesa. 
mento inicial do texto: a defesa da surdez como fenômeno eminentemente cultural que se associa à proposição de espaços exclusivos para os alunos que a apresentam e à crítica sistemática dirigida às propostas de inclusão escolar; a ênfase na compreensão de que a surdez se constitui como um fenômeno de múltipla determinação, com efeitos muito diferenciados em termos do uso de recursos de comunicação, vinculada à indicação de que os espaços compartilhados entre surdos e ouvintes deveriam ser alvo de investimento, assim como o uso de variados meios envolvendo principalmente a Libras e a Língua Portuguesa.

No caminho trilhado em busca de respostas para as questóes geradoras deste trabalho, verificamos que, no período analisado, ocorreu um aumento significativo de matrículas dos alunos com surdez no Ensino Regular, com maior ênfase nos Estados do Espírito Santo e de São Paulo, e em menor proporção no Estado do Rio Grande do Sul.

Observou-se a existência de possíveis nexos entre essa configuração escolar da distribuição de matrículas e os dados apresentados pelas produçóes acadêmicas. Tais dados indicam que os pesquisadores da UFES e da UFSCar procuraram, ao longo do período delimitado, investigar as demandas existentes nas escolas de Ensino Regular, problematizando em suas reflexôes a exigência de novos cargos, a contratação de profissionais especialistas na área da surdez e a implementação de novos espaços educativos. No âmbito dessas investigaçóes, há a problematização relativa ao papel exercido pelos tradutores intérpretes de língua de sinais, pois o número elevado de estudos que abordaram essa temática, mesmo que de forma indireta, evidencia a importância desse profissional para implementação de propostas educacionais efetivamente bilíngues marcadas pela circulação e pela aprendizagem da Libras e da Língua Portuguesa.

Em modo diferente das tendências associadas aos trabalhos dessas duas instituiçóes, as pesquisas realizadas na UFRGS procuraram, na grande maioria dos casos, reafirmar a defesa de uma educação bilíngue que se dedique ao ensino da Libras e da Língua Portuguesa em escolas especializadas somente para alunos com surdez. Essa perspectiva tende a se justificar em função da importância atribuída à dimensão cultural e dos processos vinculados a uma identidade e de pertencimento grupal.

Ao analisarmos os eixos temáticos emergentes na presente investigação, podemos perceber que o debate contemporâneo vinculado à produção acadêmica tende ainda a polarizar as alternativas compreensivas sobre os sujeitos e sobre os espaços de escolarização. Consideramos de fundamental importância o investimento na compreensão acerca de quem é o aluno com surdez, analisando suas singularidades e oferecendo a esse aluno o complexo sistema de apoios necessários quando estão em pauta as barreiras de comunicação. A afirmação do direito à es-

colarização depende desse reconhecimento e do investimento na qualificação dos processos formativos.

\section{REFERÊNCIAS}

Alberton, B. F. A. (2015). Discursos curriculares sobre educação matemática para surdos (Dissertação de Mestrado). Universidade Federal do Rio Grande do Sul, Porto Alegre, RS, Brasil.

Anais do Encontro Interinstitucional de Pesquisa: Políticas públicas e escolarização de alunos com deficiência (2014). Banco de Dados: Sorocaba/ SP: CAPES/Inep. 
Bandini, H. H. M. (2006). Avaliando aspectos de linguagem de crianças deficientes auditivas usuárias de Lingua Brasileira de Sinais (Tese de Doutorado). Universidade Federal de São Carlos, São Carlos, SP, Brasil.

Brazorotto, J. S. (2008). Crianças usuárias de implante coclear: Desempenhos acadêmicos, expectativas dos pais e dos professores (Tese de Doutorado). Universidade Federal de São Carlos, São Carlos, SP, Brasil.

Caetano, P. F. (2014). Discutindo a atuação do professor interlocutor de Libras a partir de um grupo de formação (Tese de Doutorado). Universidade Federal de São Carlos, São Carlos, SP, Brasil.

Cambruzzi, R. C. S. (2013). Recursos pedagógicos acessiveis ao aluno com surdocegueira por sindrome de Usher: Um estudo de caso (Tese de Doutorado). Universidade Federal de São Carlos, São Carlos, SP, Brasil.

Costa, L. M. (2007). Traduçôes e marcas culturais dos surdos capixabas: Os discursos descontruidos quando a resistência conta a história (Dissertação de Mestrado). Universidade Federal do Espírito Santo, Vitoria, ES, Brasil.

Costa Junior, E. R. (2015). A modelação de uma Política Cooperativa na Formação de Estudantes Surdos no Ensino Superior (Dissertação de Mestrado). Universidade Federal do Espírito Santo, Vitoria, ES, Brasil.

Cozendey, S. G. (2013). A libras no ensino de leis de Newton em uma turma inclusiva de ensino médio (Tese de Doutorado). Universidade Federal de São Carlos, São Carlos, SP, Brasil.

Damázio, M. F. M. (2007). Educação Escolar de Pessoas com Surdez: Uma proposta inclusiva (Tese de Doutorado). Faculdade de Educação, Universidade Estadual de Campinas, Campinas, SP, Brasil.

Decreto no 5.626, de 22 de dezembro de 2005. Regulamenta a Lei no 10.436, de 24 de abril de 2002. Dispóe sobre a Língua Brasileira de Sinais - LIBRAS. Recuperado em 27 de junho de 2018 de http://www.planalto.gov.br/ccivil_03/_ato2004-2006/2005/decreto/d5626.htm

Finck, R. (2009). Ensinando música ao aluno surdo: Perspectivas para ação pedagógica inclusiva (Tese de Doutorado). Faculdade de Educação, Universidade Federal do Rio Grande do Sul, Porto Alegre, RS, Brasil.

Fülber, G. G. (2012). Cartografando com uma criança surda sua infância e suas experiências educacionais (Dissertação de Mestrado). Faculdade de Educação, Universidade Federal do Rio Grande do Sul, Porto Alegre, RS, Brasil.

Furlan, L. A. (2011). Concepçôes dos professores de português sobre surdez e aluno surdo num curso de formação continuada (Dissertação de Mestrado). Universidade Federal de São Carlos, São Carlos, SP, Brasil.

Furtado, R. S. S. (2012). Narrativas Identitárias e Educação: Os surdos negros na contemporaneidade (Dissertação de Mestrado). Faculdade de Educação, Universidade Federal do Rio Grande do Sul, Porto Alegre, RS, Brasil.

Instituto Nacional de Estudos e Pesquisas Educacionais Anísio Teixeira (2016). Censo Escolar da Educação Básica. Brasília: INEP.

Jordão, U. V. (2013). O que dizem os intérpretes de Libras do sudeste goiano sobre formação e atuação (Dissertação de Mestrado). Universidade Federal de São Carlos, São Carlos, SP, Brasil. 
Kuchenbecker, L. G. (2011). Inclusão na escola de surdos: Estratégias de normalização dos sujeitos surdos Down (Dissertação de Mestrado). Faculdade de Educação, Universidade Federal do Rio Grande do Sul, Porto Alegre, RS, Brasil.

Lei no 10.436, de 24 de abril de 2002. Dispóe sobre a Língua Brasileira de Sinais - LIBRAS. Recuperado em 27 de junho de 2018 de http://www.planalto.gov.br/ccivil_03/leis/2002/110436.htm

Lima, T. C. S., \& Mioto, R. C. T. (2007). Procedimentos metodológicos na construção do conhecimento científico: A pesquisa bibliográfica. Revista Katálysis, 10 (n. esp.), 37-45.

Lodi, A. C. B. (2013). Educação bilíngue para surdos e inclusão segundo a Política Nacional de Educação Especial e o Decreto no 5.626/05. Educação e Pesquisa, 39, 49-63.

Marins, C. L. (2015). Processos de construção e desenvolvimento de currículos para surdos com deficiência em uma escola bilíngue para surdos (Dissertação de Mestrado). Faculdade de Educação, Universidade Federal do Rio Grande do Sul, Porto Alegre, RS, Brasil.

Menezes, A. M. C. (2014). Diálogos com tradutores-intérpretes de lingua de sinais (Tese de Doutorado). Universidade Federal de São Carlos, São Carlos, SP, Brasil.

Muller, P., \& Surel, Y. (2002). Análise das políticas públicas. Pelotas: EDUCAT.

Política Nacional de Educação Especial na Perspectiva da Educação Inclusiva (2008). Recuperado em 27 de junho de 2018 de http://portal.mec.gov.br/index.php?option=com_ docman\&view=download \&alias=16690-politica-nacional-de-educacao-especial-na-perspectivada-educacao-inclusiva-05122014\&Itemid $=30192$

Rabelo, D. B. (2014). O bebê surdo na educação infantil: Um olhar sobre inclusão e práticas pedagógicas (Dissertação de Mestrado). Universidade Federal do Espírito Santo, Vitoria, ES, Brasil.

Resolução SE no 38, de 19 de junho de 2009. Dispóe sobre a admissão de docentes com qualificação na Língua Brasileira de Sinais - Libras, nas escolas da rede estadual de ensino. Recuperado em 27 de junho de 2009 de http://siau.edunet.sp.gov.br/ItemLise/arquivos/38_09.HTM

Rocha, M. L. (2012). Desvelando os processos de escolarização de alunos surdos no cenário da EJA: Um estudo de caso (Dissertaçáo de Mestrado). Universidade Federal do Espírito Santo, Vitoria, ES, Brasil.

Rodrigues, E. G. (2009). A apropriação da linguagem escrita pelas crianças surdas (Dissertação de Mestrado). Universidade Federal do Espírito Santo, Vitoria, ES, Brasil.

Santos, L. F. (2014). O fazer do intérprete educacional: práticas, estratégias e criaçóes (Tese de Doutorado). Universidade Federal de São Carlos, São Carlos, SP, Brasil.

Santos, M. A. B. (2013). O professor interlocutor no contexto da educação de surdos: Aspectos da atuação deste novo profissional (Dissertação de Mestrado). Universidade Federal de São Carlos, São Carlos, SP, Brasil.

Sella, A. C. (2009). Transferência de funçôes ordinais através de classes de estímulos equivalentes: Contribuiçōes para a programaçáo de ensino de adultos e crianças surdas e de crianças ouvintes (Tese de Doutorado). Universidade Federal de São Carlos, São Carlos, SP, Brasil.

Silva, E. V. L. (2013). Narrativas de professores de surdos sobre a escrita de Sinais (Dissertação de Mestrado). Faculdade de Educação, Universidade Federal do Rio Grande do Sul, Porto Alegre, Brasil.

Silva, J. A. S. (2013). A educação da criança surda com implante coclear: Reflexóes sobre a família, a clínica e a escola (Dissertação de Mestrado). Universidade Federal do Espírito Santo, Vitoria, ES, Brasil. 
Silva, R. H. R., \& Gamboa, S. S. (2011). Análise epistemológica da pesquisa em Educação Especial: A construção de um instrumental de análise. Atos de Pesquisa em Educação, 6(2), 373-402.

Soares, C. H. R. (2011). Inclusão, surdez e Ensino Médio: Perspectivas e possibilidades para o Atendimento Educacional Especializado (Dissertaçáo de Mestrado). Universidade Federal do Rio Grande do Sul, Porto Alegre, RS, Brasil.

Suzana, E. R. B. (2014). O tradutorlintérprete de Libras em contextos de inclusão escolar: Perspectivas em uma rede municipal do Rio Grande do Sul (Dissertação de Mestrado). Faculdade de Educação, Universidade Federal do Rio Grande do Sul, Porto Alegre, RS, Brasil.

Tonello, I. M. S., Lunardelli, R. A., \& Almeida Junior, O. F. de (2012). Palavras-chave: Possibilidades de mediação da informação. Ponto de Acesso, 6(2), 21-34.

Vieira-Machado, L. M. C. (2012). (Per)cursos na formação de professores de surdos capixabas: constituição da educação bilíngue no estado do Espírito Santo (Tese de Doutorado). Universidade Federal do Espírito Santo, Vitoria, ES, Brasil.

Xavier, K. S. (2012). O lugar do intérprete educacional nos processos de escolarização do aluno surdo (Dissertação de Mestrado). Universidade Federal do Espírito Santo, Vitoria, ES, Brasil.

Recebido em: 03/03/2018

Reformulado em: 05/05/2018

Aceito em: 11/06/2018 
SOARES, C.H.R. \& BAPTISTA, C.R. 